\title{
Adsorption of Ceftazidime from Aqueous Solution by Multi-Walled Carbon Nanotubes
}

\author{
Hua Zhang, Xiang $\mathrm{Hu}^{*}$ \\ College of Chemical Engineering, Beijing University of Chemical Technology, Beijing 100029, P. R. China
}

Received: March 2, 2015

Accepted: May 5, 2015

\begin{abstract}
Antibiotic contamination of water has become a problem that cannot be ignored. However, existing water treatment technologies at home and abroad couldn't remove the antibiotics efficiently in the water environment. Our study investigated the adsorption of ceftazidime in aqueous solutions by multiwall carbon nanotubes (MWCNTs), and examined the impact of such factors as $\mathrm{pH}$ value, ion strength, and concentration of organic matter on the adsorption process. The results showed that, when the dosage of MWCNTs was $1.6 \mathrm{~g} / \mathrm{L}$ and the initial concentration of ceftazidime was $30 \mathrm{mg} / \mathrm{L}$, the removal rate of the ceftazidime came up to $80-90 \%$. The $\mathrm{pH}$ value of solution, the ion strength, and organic concentrations showed minimal or negligible impacts. The Freundlich isotherm fit the adsorption well. Kinetic analysis was conducted using models. The regression results showed that the adsorption kinetics were accurately represented by the pseudo-second order model $\left(\mathrm{R}^{2}>0.99\right)$. Based on the pseudo-second order model, the equilibrium adsorption capacity of MWCNTs was $14.79 \mathrm{mg} / \mathrm{g}$.
\end{abstract}

Keywords: adsorption, multi-walled carbon nanotubes, ceftazidime, removal

\section{Introduction}

With the rapid development of the medical industry and animal husbandry, the amount of antibiotics used for prevention and treatment of infectious diseases is increasing dramatically [1-3]. After the administration of antibiotics, a significant fraction is excreted in the parent form or its metabolite forms along with urine and feces, and then reaches aquatic environments through direct discharge of wastes [4]. In many countries these antibiotics have been found in surface water, groundwater, and even drinking water [5-7]. A large number of studies have shown that these antibiotic residues in water bodies would be harmful to all kinds of organisms and induce microbial resistance, thereby threatening environmental safety and human health $[8,9]$. Among these antibiotics, $\beta$-lactam antibiotics have become the most widely used [10].

\footnotetext{
*e-mail: huxiang@mail.buct.edu.cn
} huxiang99@163.com
Water pollution by antibiotics has become a problem that cannot be ignored. Therefore, new methods are being investigated to remove them. These treatment methods including sulfate radical oxidation [11], degradation of diclofenac by Advanced oxidation [12], solar photo-fenton [13], ozonation and $\mathrm{TiO}_{2}$ photocatalysis [14], microfiltration/reverse osmosis [15], constructed wetlands [16], nonthermal plasma treatment [17], and adsorption/bioadsorption on activated carbon [18]. Traditional water treatment technology such as biological treatment is inefficienct and may introduce by-products. Advanced oxidation is a highly effective treatment method, but it will produce toxic byproducts $[19,20]$. So the existing water treatment technology at home and abroad cannot remove the antibiotics from water efficiently and economically. Therefore, the development of an efficient removal method is necessary.

Adsorption is a commonly used method for removing organic pollutants in water, with high efficiency, low energy consumption, pollution, and other advantages [21, 22]. 
Carbon nanomaterials such as carbon nanotubes (CNTs) is a great organic pollutant adsorbent with a large surface area, high adsorption capacity, and fast adsorption equilibrium. It has been used as an adsorbent in environmental analysis, and it has great potential in the field of environmental protection and water processing [23].

CNTs have a unique structure and the special nature of nanomaterials. Its small and narrow one-dimensional hollow lumen has a strong capillary action. The tiny particles outside can be absorbed into the lumen and densely arranged. The larger surface area makes CNTs have a strong adsorption of organic compounds, and after a simple oxidation treatment the adsorption performance can be improved much more. Thus, CNTs are regarded as ideal sewage treatment agents with efficient purification [24].

In our work, multi-walled carbon nanotubes (MWCNTs) were used as adsorbents to investigate the influence of varied solution chemistry conditions, such as $\mathrm{pH}$ value, ionic strength, and concentration of organics on the adsorption. Then the mechanism of the kinetics and thermodynamics were investigated.

\section{Materials and Methods}

\section{Materials}

A pristine MWCNT was purchased from Beijing NaChen Science and Technology Development Co., Ltd., China with outer diameters of 10-30 nm, length of 10-30 nm, purity of $85 \%$, and specific surface area larger than $350 \mathrm{~m}^{2} / \mathrm{g}$. Prior to use, a portion of the pristine MWCNT was purified to remove ash content and open both ends of the cap. The MWCNT was put into a boiling flask-3-neck, then added in $5 \mathrm{~mol} / \mathrm{L}$ Nitric acid solution, and heated with stirring refluxing for eight $h$ at $100^{\circ} \mathrm{C}$. After the solution cooled to room temperature, the mixture was centrifuged and the supernatant was removed. The carbon nanotubes were rinsed with deionized water and repeated until the supernatant became neutral. Then the carbon nanotubes were oven-dried overnight to constant weight at $100^{\circ} \mathrm{C}$.

The ceftazidime (purity 85.2\%) used for the experiment was first dubbed to $200 \mathrm{mg} / \mathrm{L}$ solution, and then diluted to the certain concentration that is needed in the study. The mobile phases of HPLC were acetonitrile (imported, HPLC grade), methanol (imported, HPLC grade), and potassium dehydrogenate phosphate solution (analytical grade). The $\mathrm{pH}$ value of the potassium dehydrogenate phosphate solution was adjusted by phosphoric acid to 3.4.

\section{Instruments}

Analysis of the ceftazidime clear supernatants was performed using Shimadzu LC-20AT high-performance liquid chromatography (HPLC). The change of temperature was carried out using a SHZ-82A air bath oscillator. The $\mathrm{pH}$ value was measured by a benchtop $\mathrm{pH}$ analyzer. The glassware was dried by a DHG-9041A electric oven thermostat.
The weighing of materials was carried out using an AR2140 electronic analytical balance.

Limit of detection of HPLC was below $100 \mu \mathrm{g} / \mathrm{L}$, injection volume $=20 \mu \mathrm{L}$. Operating conditions:

- Temperature: $25^{\circ} \mathrm{C}$

- Mobile phase: $\mathrm{KH}_{2} \mathrm{PO}_{4} /$ acetonitrile $=0.125 / 0.875$

- Velocity of flow: $1 \mathrm{~mL} / \mathrm{min}$

- Chromatographic column: $4.6 \mathrm{~mm} \times 250 \mathrm{~mm}, 50 \mu \mathrm{m}$, ODS-SP

- Detection wavelength: $254 \mathrm{~nm}$

\section{Adsorption Experiments}

To examine the influence of each factor, the experiments were conducted in wide ranges. A $250 \mathrm{~mL}$ conical flask was used to carry the ceftazidime solution and was put into the oscillator with a rotation speed of $180 \mathrm{r} / \mathrm{min}$ at a constant temperature. Then the solid and liquid were separated by centrifuge. The concentration of ceftazidime in the supernatant was determined by HPLC. The adsorption amounts of ceftazidime were calculated by the concentration difference. The experiments were all performed at $25^{\circ} \mathrm{C}$.

For the determination of the amount of CNTs, different dosages of CNTs were used - from 0.02 to $0.20 \mathrm{~g}$. In the experiments, the concentration of ceftazidime was $30 \mathrm{mg} / \mathrm{L}$. For the investigation of $\mathrm{pH}$ effect, $\mathrm{pH}$ values were from 4 to 11. To examine the effects of ionic strength on ceftazidime adsorption, $\mathrm{Na}_{2} \mathrm{SO}_{4}$ solution was used as impact factor, and the concentration ranged from 0.02 to $0.2 \mathrm{~mol} / \mathrm{L}$, and bottle without any $\mathrm{Na}_{2} \mathrm{SO}_{4}$ solution was served as blanks. The organic compound in the experiment was glucose, and its concentration differs from 0 to $10 \mathrm{~g} / \mathrm{L}$. For the Kinetic experiments, the bottles with certain concentration of ceftazidime and certain amount of MWCNT were put into the oscillator for $90 \mathrm{~min}$, which was to make the adsorption reach equilibrium by preliminary kinetic experiments.

\section{Isotherm Modeling}

Three widely used isotherm models - Langmuir, Freundlich, and Tempkin - were examined to fit the experimental data. The Langmuir isotherm model is based on two assumptions:

1) All adsorption sites of solid surface were the same nature and uniform distribution. The activation energy of adsorption sites does not change with adsorption coverage changes.

2) The adsorption is monolayer. When there is only one kind of adsorption site on the surface of the adsorbent, this model can be expressed as follows:

$$
\frac{1}{\mathrm{Q}_{\mathrm{e}}}=\frac{1}{\mathrm{Q}_{\mathrm{m}}}+\frac{1}{\mathrm{~K}_{1} \mathrm{Q}_{\mathrm{m}} \mathrm{C}_{\mathrm{e}}}
$$

The Freundlich model is just an empirical formula. In consideration of the free energy of adsorption changes with the adsorption fraction, the Freundlich isotherm can be 
described as adsorption behavior for an uneven surface or the adsorbate on the surface adsorption site interactions. Its expression is given as follows:

$$
\ln \mathrm{Q}_{\mathrm{e}}=\ln \mathrm{K}_{\mathrm{F}}+\frac{1}{\mathrm{n}} \ln \mathrm{C}_{\mathrm{e}}
$$

The Tempkin model is also multi-molecular-layer adsorption and is described as follows:

$$
\mathrm{Q}_{\mathrm{e}}=\frac{\mathrm{RT}}{\mathrm{b}_{\mathrm{T}}}\left(\ln \mathrm{K}_{\mathrm{T}}+\ln \mathrm{C}_{\mathrm{e}}\right)
$$

Simplified relationship:

$$
\mathrm{Q}_{\mathrm{e}}=\mathrm{B} \ln \mathrm{K}_{\mathrm{T}}+\mathrm{B} \ln \mathrm{C}_{\mathrm{e}}
$$

...where $\mathrm{Q}_{\mathrm{e}}$ is the equilibrium concentration of the adsorbate in sorbent, $\mathrm{mg} \cdot \mathrm{g}^{-1} ; \mathrm{C}_{\mathrm{e}}$ is the concentration remaining in solution at equilibrium, $\mathrm{mg} \cdot \mathrm{L}^{-1} ; \mathrm{Q}_{\mathrm{m}}$ is the maximum amount of adsorption equilibrium, $\mathrm{mg} \cdot \mathrm{g}^{-1} ; \mathrm{K}_{1}$ is Langmuir equilibrium constant; $\mathrm{K}_{\mathrm{F}}$ is capacity factor, which indicates solid adsorbent capacity at a specific concentration of a solute; $n$ is the exponential factor, which indicates Freundlich adsorption index, and also describes a nonlinear degree of adsorption isotherm; $\mathrm{K}_{\mathrm{T}}$ is a constant of Tempkin adsorption isotherm; $\mathrm{B}$ is the adsorption constant, $\mathrm{B}=\mathrm{RT} / \mathrm{b}_{\mathrm{T}}$.

\section{Data Analysis}

Removal of the sample is calculated as follows:

$$
\eta=\left(C_{0}-C_{t}\right) / C_{0} \times 100 \%
$$

...where $\eta$ is removal efficiency of the sample at time t, \%; $\mathrm{C}_{0}$ is the concentration of stock solution, $\mathrm{mg} \cdot \mathrm{L}^{-1} ; \mathrm{C}_{\mathrm{t}}$ concentration of the sample at time $\mathrm{t}, \mathrm{mg} \cdot \mathrm{L}^{-1}$.

Adsorption capacity is calculated as follows:

$$
\mathrm{Q}_{\mathrm{t}}=\mathrm{V}\left(\mathrm{C}_{0}-\mathrm{C}_{\mathrm{t}}\right) / \mathrm{m}
$$

...where $\mathrm{Q}_{\mathrm{t}}$ is the adsorption capacity of carbon nanotubes at time $\mathrm{t}, \mathrm{mg} \cdot \mathrm{g}^{-1} ; \mathrm{V}$ is volume of the solution, $\mathrm{L} ; \mathrm{m}$ is the amount of carbon nanotubes, $\mathrm{g}$.

a)

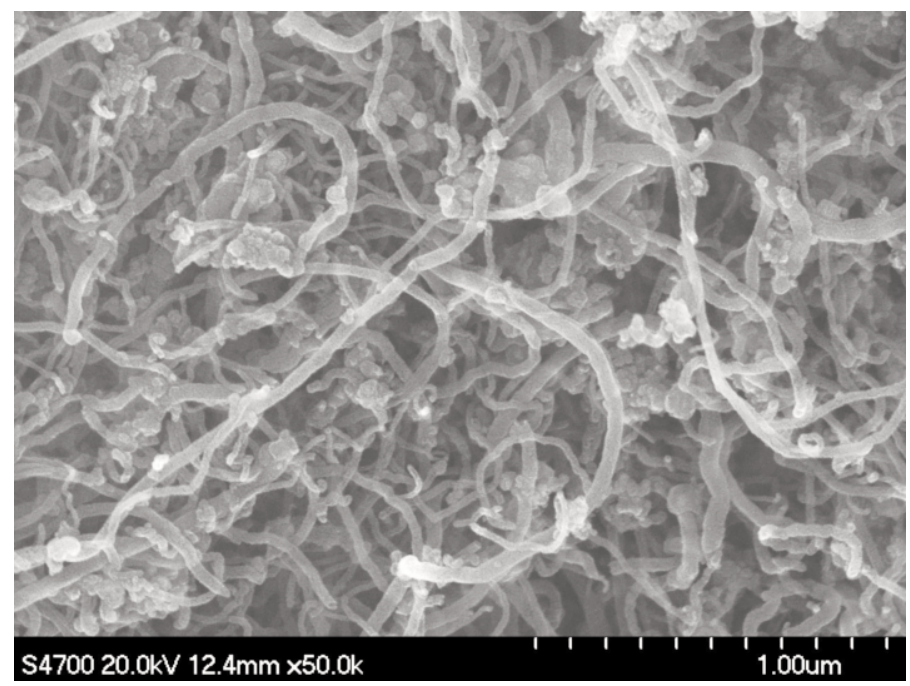

b)

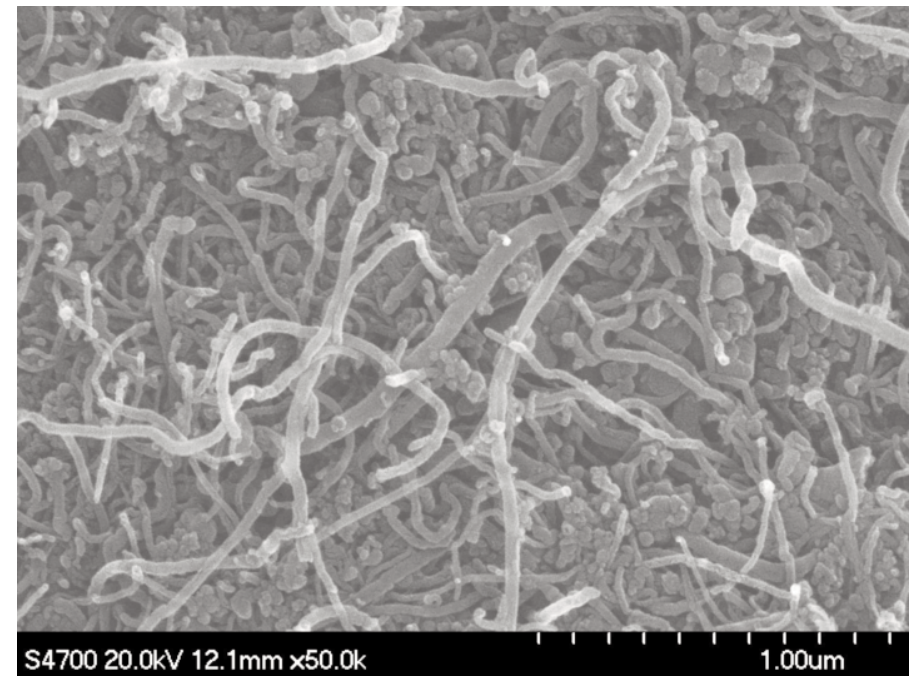

Fig. 1. SEM micrographs of unpurified MWCNTs (a) and purified MWCNTs (b). 


\section{Results and Discussion}

\section{The SEM Morphology of Unpurified and Purified MWCNTs}

During the manufacturing process of MWCNTs, because of the use of a metal catalyst, the finished product might have a certain amount of metal catalyst residue and by-products. Thus the purity and the nature of MWCNTs would be affected to a certain extent. Therefore, in order to remove the metal catalyst and by-products and guarantee the purity and the nature of the MWCNTs, it was necessary to purify the MWCNTs.

Fig. 1a shows a SEM image of unpurified MWCNTs and Fig. 1b shows a SEM image of purified MWCNTs. Comparing these two pictures we found that the surface of MWCNTs before purification showed some of the larger particles of impurities clearly. After nitric acid treatment, MWCNTs were cut much shorter and less particulate matter, which led to greater surface area. In addition, MWCNTs had more active sites, better dispersion, and enhanced hydrophilic properties, which all contribute to the improvement adsorption performance.

\section{Effect of MWCNT Dosage}

The effect of MWCNT dosage is shown in Fig. 2. With increasing MWCNT doses (0.02 g-0.2 g), removal efficiency increased while adsorption amounts decreased. When the dose reached $0.08 \mathrm{~g}(1.6 \mathrm{~g} / \mathrm{L})$, removal efficiency approached $80 \%$. Then as it kept on increasing, efficiency would still increase, but the amplitude decreased. Therefore, taking the removal efficiency and economic considerations into consideration, the appropriate dose was $0.08 \mathrm{~g}(1.6 \mathrm{~g} / \mathrm{L})$.

The increasing doses of MWCNTs resulted in the removal of ceftazidime due to the dilute solution MWCNTs showing a dispersion state. At this time, as the increasing

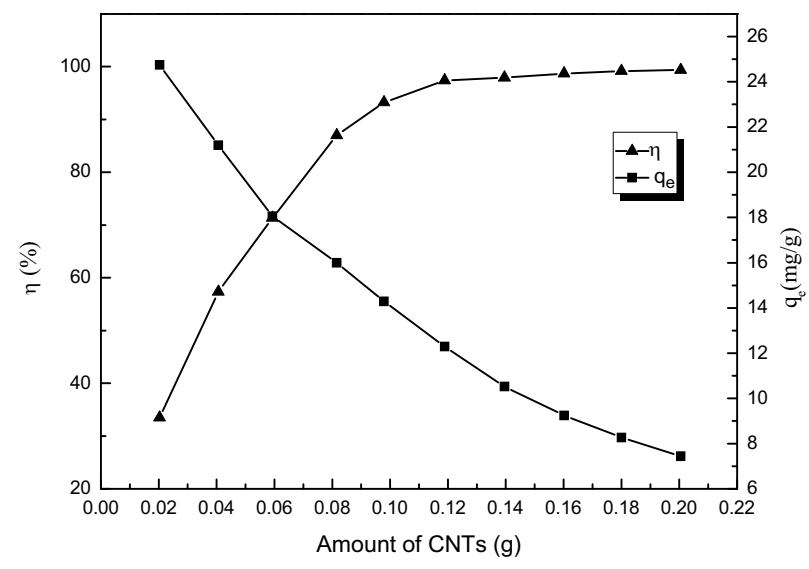

Fig. 2. Effect of the amount of MWCNTs on removal rate and adsorption capacity of ceftazidime.

Notes: experimental conditions, $298 \mathrm{~K}, 180 \mathrm{r} / \mathrm{min}, 60 \mathrm{~min}$, concentration of ceftazidime: $30 \mathrm{mg} / \mathrm{L}$, dosages of MWCNTs: 0.02$0.20 \mathrm{~g}$.

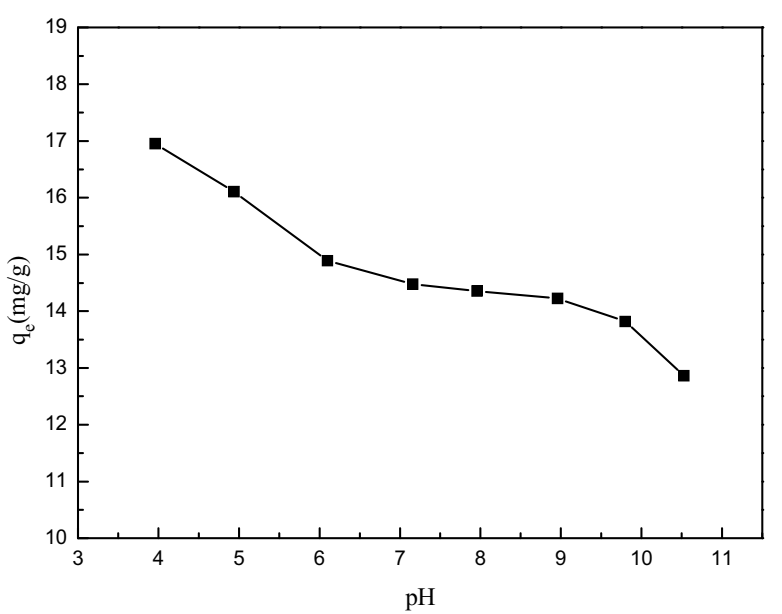

Fig. 3. Effect of $\mathrm{pH}$ on the adsorption of ceftazidime by MWCNTs.

Notes: experimental conditions, $298 \mathrm{~K}, 180 \mathrm{r} / \mathrm{min}, 60 \mathrm{~min}$, concentration of ceftazidime: $30 \mathrm{mg} / \mathrm{L}$, dosages of MWCNTs: $0.08 \mathrm{~g}$, pH values: 4-11.

amount of MWCNTs, not only the surface area of MWCNTs increased (getting a large number of adsorption sites), but also the number of functional groups involved in adsorption increased. However, when the amount of MWCNTs reached a certain extent, the increase of removal efficiency leveled off and reached equilibrium. The reason might be that the collision probability of MWCNTs increased in the aqueous solution, leading to adsorbent particle congestion and the adsorption sites overlapping. Then it hinders aggregation of adsorbate on the surface of MWCNTs. Furthermore, the large dose of MWCNTs would cause the increase of solid-liquid the viscous of suspensions, and also inhibit adsorbate molecule diffusion into the surface of MWCNTs.

\section{Effect of $\mathrm{pH}$ Value}

One of the significant factors of adsorption is $\mathrm{pH}$ and the effect of the state of charge of functional groups on the adsorbent surface. As shown in Fig. 3, with $\mathrm{pH}$ increased, removal efficiency decreased. This means that acidic conditions were more suitable for adsorption. The ceftazidime solution was slightly acidic, so the actual operation was taken into account, with the original mother liquor ( $\mathrm{pH}=4.21)$ as the most suitable conditions.

Apparently, maximum adsorption happened at low $\mathrm{pH}$ value, which had much related with the form of ceftazidime and the charge of MWCNT surfaces [25]. Both of them were highly dependent on solution $\mathrm{pH}$. When the $\mathrm{pH}$ was close to zero charge of the MWCNTs $\left(\mathrm{pH}_{\mathrm{PZC}}\right)$, the surface charge density of MWCNTs was close to zero. And the ceftazidime $\left(\mathrm{pK}_{\mathrm{al}}=2.77\right)$ existed in molecular form, thus strengthening the $\pi-\pi$ interaction between MWCNTs and ceftazidime. When $\mathrm{pH}$ increased, the ceftazidime deprotonated, and the repulsive electrostatic properties between MWCNTs and ceftazidime increased. When the solution $\mathrm{pH}$ was 5-7, the ceftazidime $\left(\mathrm{pK}_{\mathrm{a} 2}=4.26\right)$ species changed 
again, which was more unfavorable for sorption. In addition, as the solution increased, the $\mathrm{OH}$ - would compete the adsorption site with negatively charged ceftazidime, leading to the decreasing adsorption dosage of ceftazidime.

\section{Effects of Ionic Strength}

In the solution with the presence of electrolytes, adsorbate-adsorbent interaction strength will change for two reasons:

1) Electric double layer theory. When the solid adsorbent is used in a water treatment process, an electric double layer will form between the solid and liquid [26]. This will hinder the adsorbate adsorbed to the surface of the adsorbent. The thickness of the electric double layer will be affected by the ionic strength; an increase of ionic strength can reduce the amount of adsorption.

2) Synergistic effects. Ions were first adsorbed onto activated carbon; higher ionic strength can produce a kind of surface charge shielding effect and is advantageous to the $\pi-\pi$ conjugate effect, thereby enhancing ceftazidime adsorption. In this study, $\mathrm{Na}_{2} \mathrm{SO}_{4}$ solution was used to influence factors. The effect of ionic strength is shown in Fig. 4. As the concentration of $\mathrm{Na}_{2} \mathrm{SO}_{4}$ in the system increased, the adsorption capacity of ceftazidime to the CNTs increased gradually. That might because the second theory was the primary cause.

\section{Effect of Organics on Adsorption}

Organics are common in the aquatic environment, so considering the organics effect was necessary. Some studies showed that organics might be competitive for adsorption in two aspects:

1) directly competitive adsorption sites,

2) blocking holes of adsorbent and the pore volume and the surface area of the adsorbent reduced.

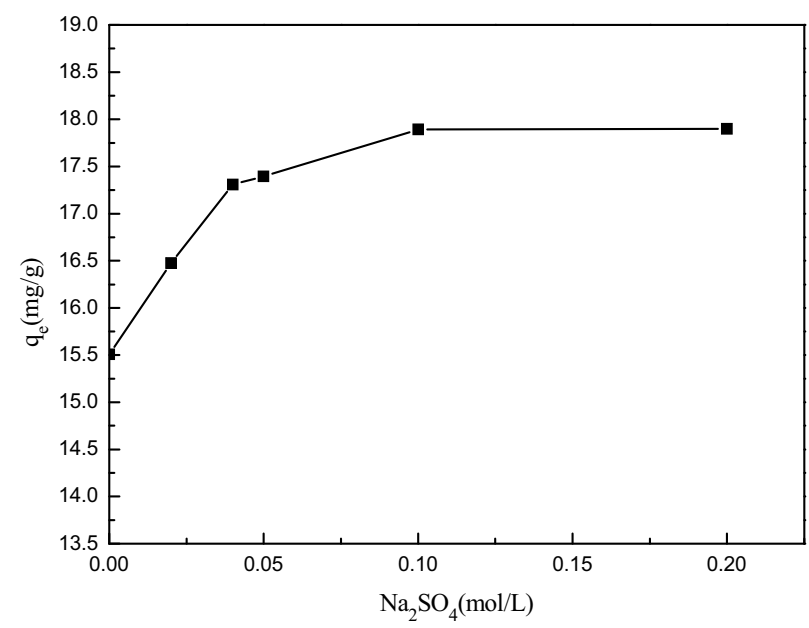

Fig. 4. Effect of ionic strength on the adsorption of ceftazidime by MWCNTs.

Notes: experimental conditions, $298 \mathrm{~K}, 180 \mathrm{r} / \mathrm{min}, 60 \mathrm{~min}$, concentration of ceftazidime: $30 \mathrm{mg} / \mathrm{L}$, dosages of MWCNTs: $0.08 \mathrm{~g}$, concentration of $\mathrm{Na}_{2} \mathrm{SO}_{4}$ solution: $0.02-0.2 \mathrm{~mol} / \mathrm{L}$.

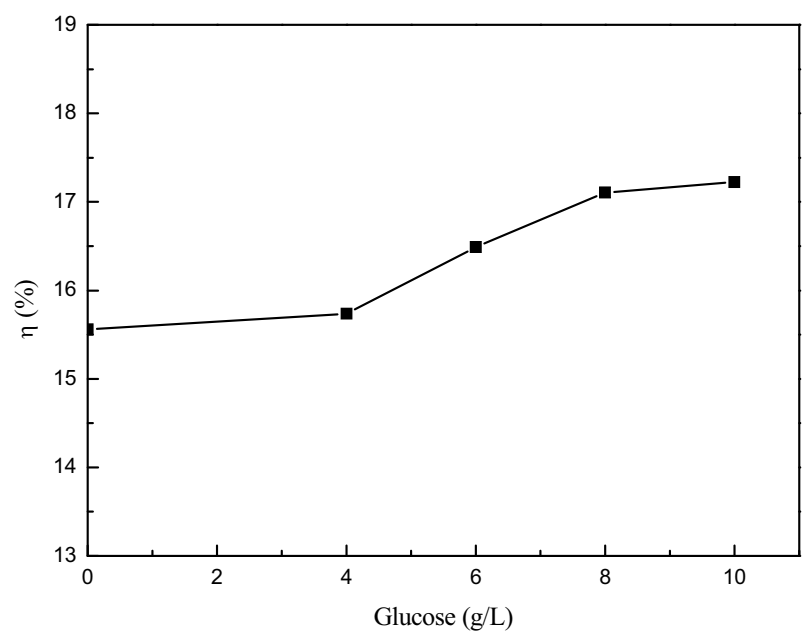

Fig. 5. Effect of concentration of organic matter on the adsorption of ceftazidime by MWCNTs.

Notes: experimental conditions, $298 \mathrm{~K}, 180 \mathrm{r} / \mathrm{min}, 60 \mathrm{~min}$, concentration of ceftazidime: $30 \mathrm{mg} / \mathrm{L}$, dosages of MWCNTs: $0.08 \mathrm{~g}$, concentration of glucose solution: $0-10 \mathrm{~g} / \mathrm{L}$.

In the study, glucose was chosen as the representative of the organic matter because, for the existing activated sludge system, glucose was on behalf of the readily biodegradable organics. In Fig. 5, the organics showed a positive effect on the adsorption, indicating that neither of these competitions happened, or they did not played a key role in the adsorption. This positive effect can be ignored.

\section{Effect of Contact Time}

As observed from Fig. 6, the adsorption rate of ceftazidime was very fast. In the initial $10 \mathrm{~min}$ of adsorption, the removal rate reached about $70 \%$. Then the rate slowed down, and after 60 min adsorption, about $80 \%$ of ceftazidime was removed and the adsorption reached equilib-

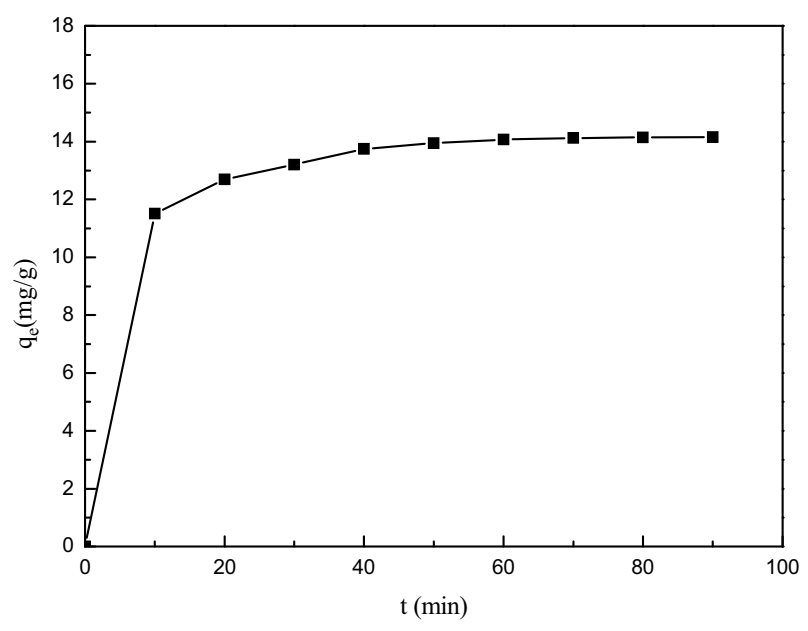

Fig. 6. Effect of time on the adsorption of ceftazidime by MWCNTs.

Notes: experimental conditions, $298 \mathrm{~K}, 180 \mathrm{r} / \mathrm{min}, 90 \mathrm{~min}$, concentration of ceftazidime: $30 \mathrm{mg} / \mathrm{L}$, dosages of MWCNTs: $0.08 \mathrm{~g}$ 
Table 1. Constants of Freundlich, Langmuir and Temkin isotherm models for ceftazidime removal by MWCNTs.

\begin{tabular}{|c|c|c|c|}
\hline \multirow{2}{*}{ Temperature } & \multicolumn{3}{|c|}{ Langmuir isotherm } \\
\cline { 2 - 4 } & $\mathrm{K}_{1}(\mathrm{~L} / \mathrm{mg})$ & $\mathrm{Q}_{\mathrm{m}}$ & $\mathrm{R}^{2}$ \\
\hline $293 \mathrm{~K}$ & 1.36 & 16.18 & 0.9641 \\
\hline $303 \mathrm{~K}$ & 1.61 & 13.87 & 0.8938 \\
\hline $313 \mathrm{~K}$ & 1.18 & 14.04 & 0.9420 \\
\hline \multirow{3}{*}{} & \multicolumn{3}{|c|}{ Freundlich isotherm } \\
\cline { 2 - 4 } & $\mathrm{K}_{\mathrm{F}}$ & $\mathrm{n}$ & $\mathrm{R}^{2}$ \\
\hline $293 \mathrm{~K}$ & 8.46 & 3.38 & 0.9894 \\
\hline $303 \mathrm{~K}$ & 7.68 & 3.24 & 0.9983 \\
\hline $313 \mathrm{~K}$ & 7.03 & 3.16 & 0.9948 \\
\hline \multirow{2}{*}{} & & Tempkin \\
\cline { 2 - 4 } & $\mathrm{K}_{\mathrm{T}}$ & $\mathrm{B}$ & $\mathrm{R}^{2}$ \\
\hline $293 \mathrm{~K}$ & 13.22 & 3.39 & 0.9863 \\
\hline $303 \mathrm{~K}$ & 11.60 & 3.23 & 0.9740 \\
\hline $313 \mathrm{~K}$ & 10.55 & 3.04 & 0.9771 \\
\hline
\end{tabular}

rium. At the initial stage, a large number of surface sites on the CNTs were available for adsorption, so the adsorption speed is quite fast. But with the increase of the ceftazidime adsorbed onto the surface, repulsive force was generated between the ceftazidime molecule on the CNTs and the one in the solution. So the remaining space was hard to be occupied, and resulted in absorption saturation. From the above results, 60 min was used as adsorption equilibrium time of ceftazidime in the subsequent tests.

\section{Adsorption Isotherms}

The adsorption isotherms at different temperatures are given in (see supplementary material S1-S3). The parameters of three isotherm equations and fitting correlation coefficient $\mathrm{R}^{2}$ determined from linear plots of the isotherm models are summarized in Table 1 . Comparing the $\mathrm{R}^{2}$ values listed in Table 1 indicates that the Freundlich isotherm fits the experimental data better. It is suggested that the sorption is a multilayer process. $\mathrm{K}_{\mathrm{F}}$ decreased with temperature, indicating that the sorption of ceftazidime onto CNTs decreased with temperature. The result suggested that the affinity of the binding sites for CNTs decreased with temperature.

Taking the constants of the Tempkin into consideration, $\mathrm{K}_{\mathrm{T}}$ decreases with temperature, indicating that the sorption capacity decreases as the temperature goes up. Both the Freundlich and Tempkin isotherms reveal that the increasing temperature decreased the sorption capacity, which can lead to the conjecture that the sorption is exothermic. The next section analyzes the thermodynamic parameters.
Table 2. Thermodynamic parameters for ceftazidime adsorption by MWCNTs.

\begin{tabular}{|c|c|c|c|}
\hline $\mathrm{T}(\mathrm{K})$ & $\Delta \mathrm{G}(\mathrm{kJ} / \mathrm{mol})$ & $\Delta \mathrm{H}(\mathrm{kJ} / \mathrm{mol})$ & $\Delta \mathrm{S}(\mathrm{J} / \mathrm{mol} / \mathrm{K})$ \\
\hline 293 & -17.99 & -11.85 & 20.92 \\
\hline 303 & -18.18 & -11.85 & 20.92 \\
\hline 313 & -18.41 & -11.85 & 20.92 \\
\hline
\end{tabular}

\section{Adsorption Thermodynamic}

The thermodynamic parameters for the adsorption of ceftazidime onto CNTs were studied to gain in-depth information about the inherent energetic changes. The parameters included in the change in free energy $(\Delta \mathrm{G})$, enthalpy $(\Delta H)$, and entropy $(\Delta S)$ were calculated by the following equations:

$$
\begin{gathered}
\Delta \mathrm{G}=-\mathrm{RT} \ln \left(\mathrm{K}_{\mathrm{D}}\right) \\
\ln \left(\mathrm{K}_{\mathrm{D}}\right)=\frac{\Delta \mathrm{S}}{\mathrm{R}}-\frac{\Delta \mathrm{H}}{\mathrm{RT}} \\
\mathrm{K}_{\mathrm{D}}=\frac{\mathrm{q}_{\mathrm{e}}}{\mathrm{C}_{\mathrm{e}}}
\end{gathered}
$$

...where $\mathrm{R}$ is the universal gas constant ( $8.314 \mathrm{~J} / \mathrm{mole} \mathrm{K})$, $\mathrm{T}$ is temperature $(\mathrm{K})$, and $\mathrm{K}_{\mathrm{D}}$ is the distribution coefficient for the adsorption.

These thermodynamic parameters are presented in Table 2. The negative values of $\Delta \mathrm{G}$ indicate the spontaneous nature for the adsorption process. The increase in $\Delta \mathrm{G}$ values with increasing temperature shows an increase in the possibility of adsorption at lower temperatures. The obtained $\Delta \mathrm{H}$ value reveals the exothermic nature of ceftazidime adsorption. The physisorption nature of ceftazidime on CNT can also be concluded from the value of $\Delta \mathrm{H}$. The negative $\Delta \mathrm{S}$ value suggests spontaneity during the adsorption process.

\section{Adsorption Kinetics}

To determine the ceftazidime adsorption process on CNTs, three kinetic equations - pseudo-zero, pseudo-firstorder, and pseudo-second-order - were examined to fit the experimental data:

Table 3. Constants of pseudo-zero, pseudo-first-order, pseudosecond-order, and Weber-Morris particle dispersion models for ceftazidime removal by MWCNTs.

\begin{tabular}{|l|c|c|c|c|}
\hline \multicolumn{1}{|c|}{ Models } & $\mathrm{q}_{\mathrm{e}}(\mathrm{mg} / \mathrm{g})$ & $\mathrm{C}$ & $\mathrm{k}$ & $\mathrm{R}^{2}$ \\
\hline Pseudo-zero & 14.44 & - & -30.5 & 0.8845 \\
\hline Pseudo-first-order & 4.037 & - & 0.0306 & 0.9748 \\
\hline Pseudo-second-order & 14.79 & - & 0.0211 & 0.9998 \\
\hline $\begin{array}{l}\text { Weber-Morris particle } \\
\text { dispersion }\end{array}$ & - & 10.012 & 0.5572 & 0.9502 \\
\hline
\end{tabular}


Table 4. Comparison of our findings with previous materials used for the removal of antibiotics from aqueous solution.

\begin{tabular}{|l|c|c|c|c|c|}
\hline \multicolumn{1}{|c|}{ Adsorbent } & Types of antibiotics & Initial concentration & $\mathrm{q}_{\mathrm{e}}$ & Equilibrium time & Reference \\
\hline MWCNTs & ceftazidime & $30 \mathrm{mg} / \mathrm{L}$ & $14.79 \mathrm{mg} / \mathrm{g}$ & $60 \mathrm{~min}$ & Our work \\
\hline Activated carbons & cephalexin & $16 \mathrm{mg} / \mathrm{L}$ & $29.9 \mathrm{mg} / \mathrm{g}$ & $60 \mathrm{~h}$ & {$[25]$} \\
\hline Montmorillonite and kaolinite & nalidixic acid & $12 \mathrm{mg} / \mathrm{L}$ & $24 \mathrm{mg} / \mathrm{g}$ & $24 \mathrm{~h}$ & {$[26]$} \\
\hline Magnetic mesoporous silica spheres & sulfamethazine & $0.10 \mathrm{mmol} / \mathrm{L}$ & $0.0231 \mathrm{mmol} / \mathrm{g}$ & $12 \mathrm{~h}$ & {$[27]$} \\
\hline
\end{tabular}

$$
\begin{gathered}
\mathrm{q}_{\mathrm{t}}=\frac{\mathrm{k}_{0}}{\mathrm{t}}+\mathrm{q}_{\mathrm{e}} \\
\ln \left(\mathrm{q}_{\mathrm{e}}-\mathrm{q}_{\mathrm{t}}\right)=\ln \mathrm{q}_{\mathrm{e}}-\mathrm{k}_{1} \mathrm{t} \\
\frac{\mathrm{t}}{\mathrm{q}_{\mathrm{t}}}=\frac{1}{\mathrm{k}_{2} \mathrm{q}_{\mathrm{e}}^{2}}+\frac{\mathrm{t}}{\mathrm{q}_{\mathrm{e}}}
\end{gathered}
$$

...where $\mathrm{q}_{\mathrm{t}}$ is the adsorption capacity of carbon nanotubes at time $\mathrm{t}, \mathrm{mg} \cdot \mathrm{g}^{-1} ; \mathrm{t}$ is time, $\min ; \mathrm{q}_{\mathrm{e}}$ is the equilibrium adsorption capacity of carbon nanotubes, $\mathrm{mg} \cdot \mathrm{g}^{-1} ; \mathrm{k}_{0}, \mathrm{k}_{1}$, and $\mathrm{k}_{2}$ are constants.

The Weber-Morris particle dispersion model is used to describe the diffusion mechanism of particles inside the porous structure; this can be expressed as follows:

$$
\mathrm{q}_{\mathrm{t}}=\mathrm{K}_{\mathrm{id}} \mathrm{t}^{\frac{1}{2}}+\mathrm{C}
$$

...where $\mathrm{K}_{\mathrm{id}}$ is the rate constant of internal particle diffusion; $\mathrm{C}$ is a constant, if $\mathrm{C} \neq 0$, diffusion of the particles inside is not the only control step of the adsorption rate. Otherwise it is the only control step.

The parameters for pseudo-zero, pseudo-first-order, pseudo-second-order, and Weber-Morris particle dispersion models are listed in Table 3. The results (see supplementary material S4-S7) showed that the adsorption of ceftazidime on MWCNTs fit well with pseudo-second-order, the correlation coefficient $\mathrm{R}^{2}$ was above 0.99 . From the result, the equilibrium adsorption capacity qe can be obtained, which was $14.79 \mathrm{mg} / \mathrm{g}$, and the adsorption rate constant $\mathrm{k}_{2}$ was $0.0213 \mathrm{~g} /(\mathrm{mg} \cdot \mathrm{min})$.

\section{Reuse and Comparison with Other Adsorbents}

After the adsorption of ceftazidime, the adsorbent was filtered and put in the deionized water for desorption. Then the MWCNTs were dried for sorption again. The cyclic could be done 4-5 times. The removal efficiency was dropped by $50-60 \%$, which was because the MWCNTs were difficult to recycle for the relatively light quality. It occurred to us that for further recycling, MWCNTs could be modified as magnetic materials.

There was barely research about the adsorption of ceftazidime in water. Some studied the adsorption of other antibiotics in water by different adsorbents. The comparison of our findings with previous materials used for the removal of antibiotics from aqueous solution are listed in Table 4. As shown in Table 4, the adsorption capacity of ceftazidime by MWCNTs in our work was a little lower than the others. However, the equilibrium time was much shorter than the others, which was the clear advantage of our work.

\section{Conclusion}

The adsorption of ceftazidime on MWCNTs was a fast adsorption process; the adsorption capacity increased significantly in $10 \mathrm{~min}$, and $10 \mathrm{~min}$ later the growth rate of adsorption tends to slow. The adsorption had reached equilibrium within $60 \mathrm{~min}$, which can be chosen as the adsorption time. The optimum MWCNT dosage was $0.08 \mathrm{~g}$ $(1.6 \mathrm{~g} / \mathrm{L})$, at that time the removal was $80-90 \%$, and the adsorption capacity was $15.24 \mathrm{mg} / \mathrm{g}$. As $\mathrm{pH}$ increased, the removal rate decreased, but the change was not obvious. Ionic strength and organic concentration would cause the removal rate to increase, but the effect could be ignored. The Freundlich adsorption isotherm fit the adsorption well. According to the pseudo-first-order model, the equilibrium adsorption capacity qe was $14.79 \mathrm{mg} / \mathrm{g}$. As the work was about the adsorption of low concentration of ceftazidime, then it was possible to extend this work in other real samples to remove antibiotics from natural water in the future.

\section{Supplementary Material Captions}

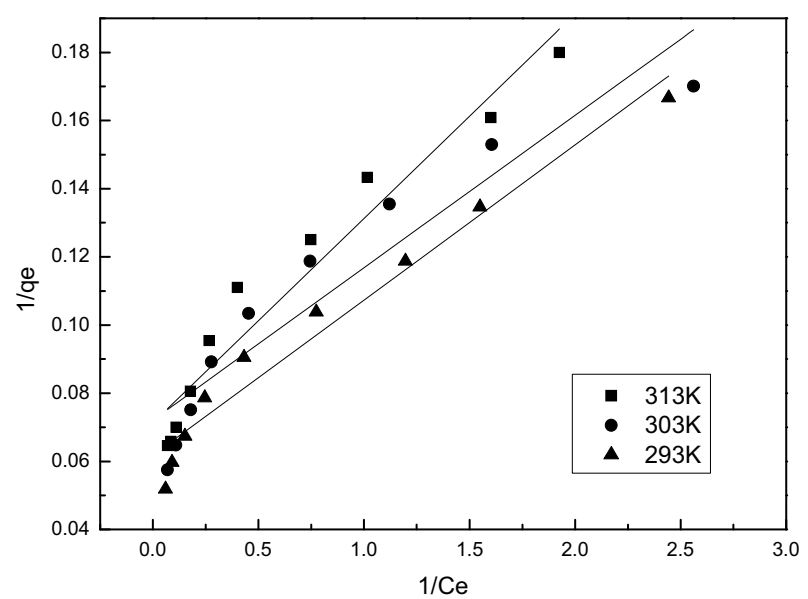

S1. Langmuir adsorption isotherms for ceftazidime removal by MWCNTs.

Notes: experimental conditions, $298 \mathrm{~K}, 180 \mathrm{r} / \mathrm{min}, 60 \mathrm{~min}$, concentration of ceftazidime: $30 \mathrm{mg} / \mathrm{L}$, dosages of MWCNTs: $0.08 \mathrm{~g}$ 


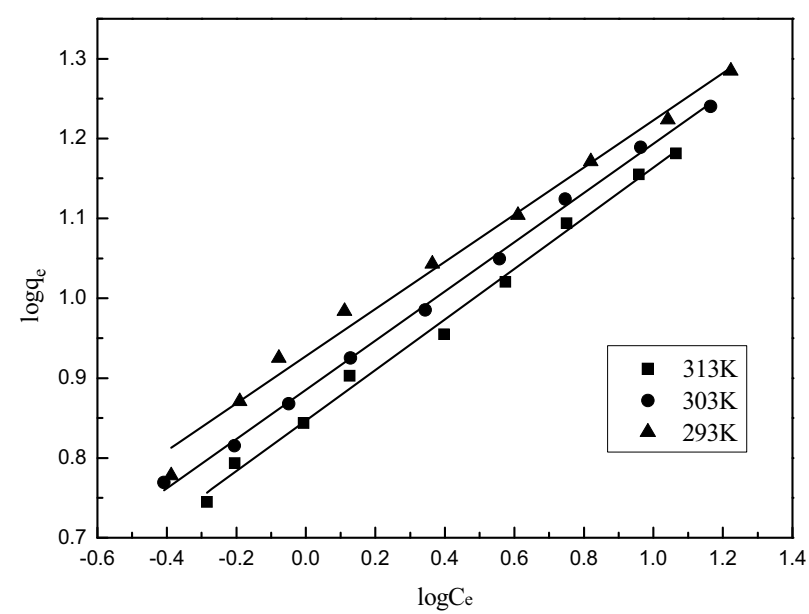

S2. Freundlich adsorption isotherms for ceftazidime removal by MWCNTs.

Notes: experimental conditions, $298 \mathrm{~K}, 180$ r/min, $60 \mathrm{~min}$, concentration of ceftazidime: $30 \mathrm{mg} / \mathrm{L}$, dosages of MWCNTs: $0.08 \mathrm{~g}$

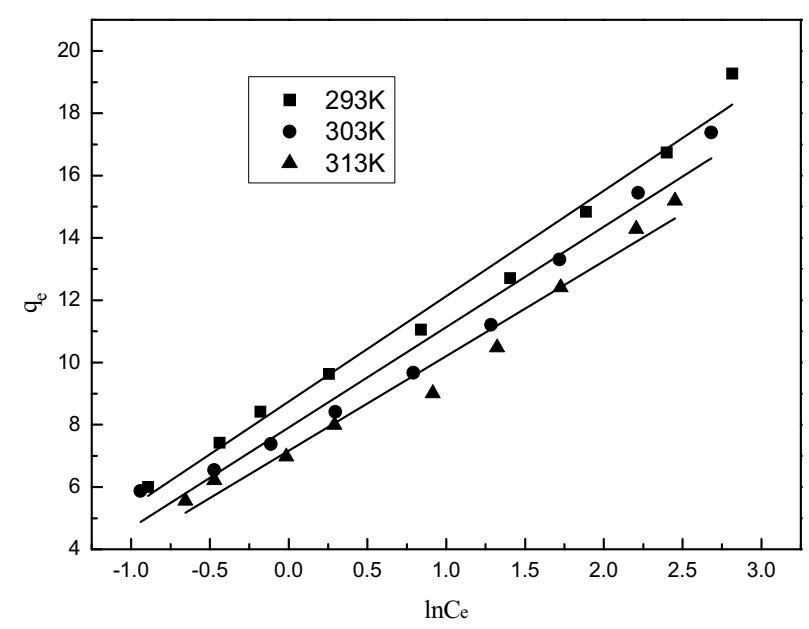

S3. Temkin adsorption isotherms for ceftazidime removal by MWCNTs.

Notes: experimental conditions, $298 \mathrm{~K}, 180 \mathrm{r} / \mathrm{min}, 60 \mathrm{~min}$, concentration of ceftazidime: $30 \mathrm{mg} / \mathrm{L}$, dosages of MWCNTs: $0.08 \mathrm{~g}$

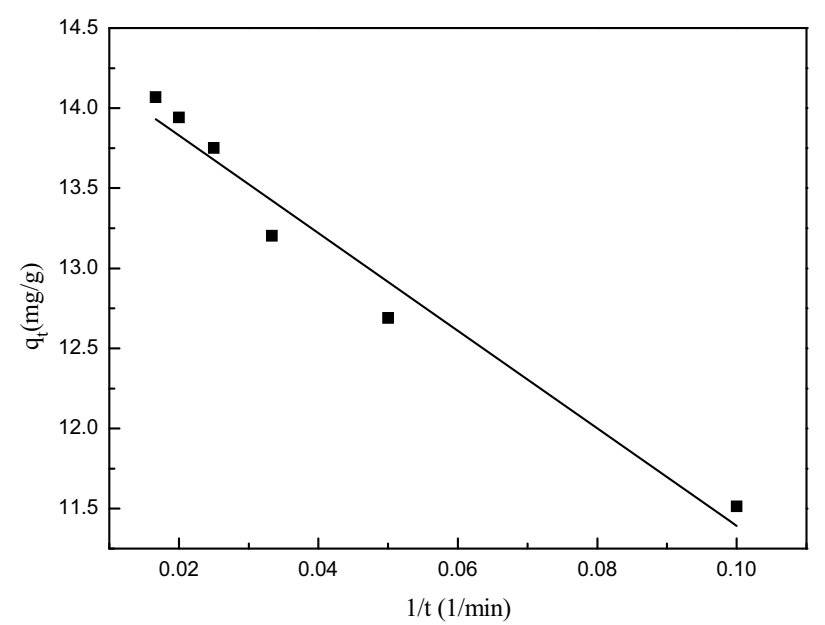

S4. Pseudo-zero models for ceftazidime removal by MWCNTs. Notes: experimental conditions, 298 K, 180 r/min, 90 min, concentration of ceftazidime: $30 \mathrm{mg} / \mathrm{L}$, dosages of MWCNTs: $0.08 \mathrm{~g}$

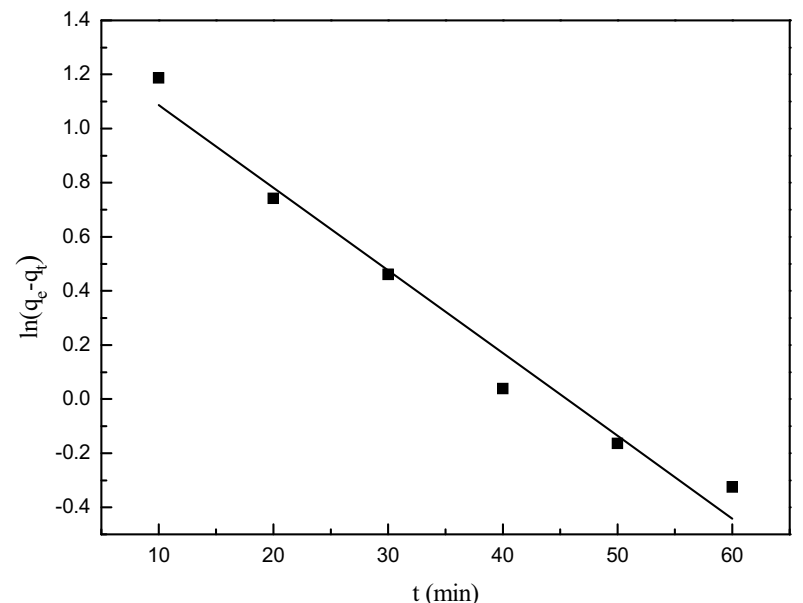

S5. Pseudo-first-order models for ceftazidime removal by MWCNTs.

Notes: experimental conditions, $298 \mathrm{~K}, 180 \mathrm{r} / \mathrm{min}, 90 \mathrm{~min}$, concentration of ceftazidime: $30 \mathrm{mg} / \mathrm{L}$, dosages of MWCNTs: $0.08 \mathrm{~g}$

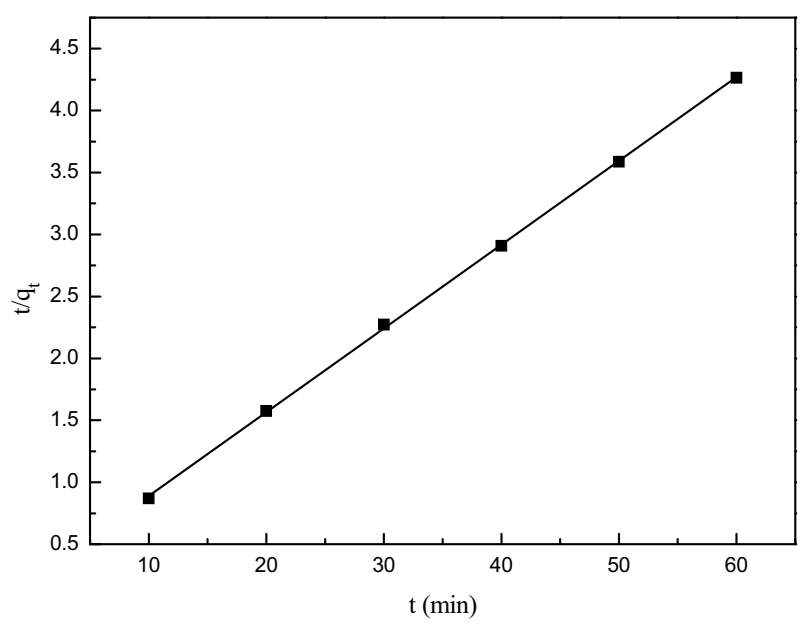

S6. Pseudo-second-order models for ceftazidime removal by MWCNTs.

Notes: experimental conditions, 298 K, 180 r/min, 90 min, concentration of ceftazidime: $30 \mathrm{mg} / \mathrm{L}$, dosages of MWCNTs: $0.08 \mathrm{~g}$

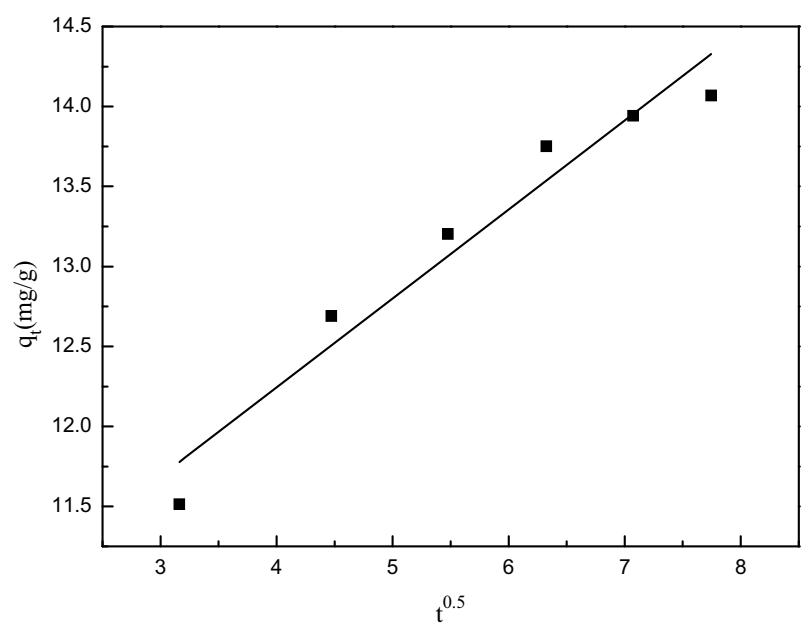

S7. Weber-Morris particle dispersion models for ceftazidime removal by MWCNTs.

Notes: experimental conditions, 298 K, 180 r/min, 90 min, concentration of ceftazidime: $30 \mathrm{mg} / \mathrm{L}$, dosages of MWCNTs: $0.08 \mathrm{~g}$ 


\section{Acknowledgements}

We thank the National Natural Science Foundation of China (Project Nos. 50878014 and 51178022) for financial support.

\section{References}

1. KÜMMERER K. Antibiotics in the aquatic environment-a review-Part I. Chemosphere. 75, (4), 417, 2009.

2. LE-MINH N., KHAN S., DREWES J., STUETZ R. Fate of antibiotics during municipal water recycling treatment processes. Water Res. 44, (15), 4295, 2010.

3. KEMPER N. Veterinary antibiotics in the aquatic and terrestrial environment. Ecological Indicators. 8, (1), 1, 2008.

4. ZHOU L., YING G., ZHAO J., YANG J., WANG L., YANG B., LIU S. Trends in the occurrence of human and veterinary antibiotics in the sediments of the Yellow River, Hai River and Liao River in northern China. Environ. Pollut. 159, (7), 1877, 2011.

5. BLACKWELL P., KAY P., ASHAUER R., BOXALL A. Effects of agricultural conditions on the leaching behaviour of veterinary antibiotics in soils. Chemosphere. 75, (1), 13, 2009.

6. ROIG B., BROGAT M., MOMPELAT S., LEVEQUE J., CADIERE A., THOMAS O. Inter- laboratory exercise on antibiotic drugs analysis in aqueous samples. Talanta. 98, 157, 2012.

7. TOGOLA A., BUDZINSKI H. Multi-residue analysis of pharmaceutical compounds in aqueous samples. J. Chromatogr. A. 1177, (1), 150, 2008.

8. SCOTT L., MCGEE P., WALSH C., FANNING S., SWEENEY T., BLANCO J., KARCZMARCZYK M., EARLEY B., LEONARD N., SHERIDAN J. Detection of numerous verotoxigenic $E$. Coli serotypes, with multiple antibiotic resistance from cattle faeces and soil. Vet. Microbiol. 134, (3-4), 288, 2009.

9. YANG Q., ZHANG J., ZHU K., ZHANG H. Influence of oxytetracycline on the structure and activity of microbial community in wheat rhizosphere soil. J. Environ. Sci. 21, (7), 954, 2009

10. ZHANG H., LIU P., FENG Y., YANG F. Fate of antibiotics during wastewater treatment and antibiotic distribution in the effluent-receiving waters of the Yellow Sea, northern China. Mar. Pollut. Bull. 73, (1), 282, 2013.

11. RICKMAN K., MEZYK S. Kinetics and mechanisms of sulfate radical oxidation of $\beta$-lactam antibiotics in water. Chemosphere. 81, (3), 359, 2010.

12. YU H., NIE E., XU J., YAN S., COOPER W., SONG W. Degradation of diclofenac by advanced oxidation and reduction processes: Kinetic studies, degradation pathways and toxicity assessments. Water Res. 47, (5), 1909, 2013.

13. MICHAEL I., HAPESHI E., MICHAEL C., VARELA A., KYRIAKOU S., MANAIA C. M., FATTA-KASSINOS D. Solar photo-Fenton process on the abatement of antibiotics at a pilot scale: Degradation kinetics, ecotoxicity and phyto- toxicity assessment and removal of antibiotic resistant enterococci. Water Res. 46, (17), 5621, 2012.

14. NASUHOGLU D., RODAYAN A., BERK D., YARGEAU $\mathrm{V}$. Removal of the antibiotic levofloxacin (LEVO) in water by ozonation and $\mathrm{TiO}_{2}$ photocatalysis. Chem. Eng. J. 189190, 41, 2012.

15. WATKINSON A., MURBY E., COSTANZO S. Removal of antibiotics in conventional and advanced wastewater treatment: Implications for environmental discharge and wastewater recycling. Water Res. 41, (18), 4164, 2007.

16. HUSSAIN S., PRASHER S. PATEL R. M. Removal of ionophoric antibiotics in free water surface constructed wetlands. Ecol. Eng. 41, 13, 2012.

17. MAGUREANU M., PIROI D., MANDACHE N., DAVID V., MEDVEDOVICI A., BRADU C., PARVULESCU V. Degradation of antibiotics in water by non-thermal plasma treatment. Water Res. 45, (11), 3407, 2011.

18. RIVERA-UTRILLA J., PRADOS-JOYA G., SÁNCHEZPOLO M., FERRO-GARCÍA M., BAUTISTA-TOLEDO I. Removal of nitroimidazole antibiotics from aqueous solution by adsorption/bioadsorption on activated carbon. J. Hazard Mater. 170, (1), 298, 2009.

19. TIAN Z., XU J., LI L., ZHANG Y., HE Y., GUO C. Adsorption of carbamazepine on montmorillonite KSF. Fresen. Environ. Bull. 21, 2201, 2012.

20. LEODOPOULOS C., DOULIA D., GIMOUHOPOULOS K. Study on adsorption behavior of humic acid on acidified montmorillonite: kinetic and equilibrium modeling, comparison of linear and non-linear methods. Fresen. Environ. Bull. 22, 228, 2013.

21. BAYRAM E., HODA N., AYRANCI E. Adsorption/electrosorption of catechol and resorcinol onto high area activated carbon cloth. J. Hazard Mater. 168, (2-3), 1459, 2009.

22. RAMOS M., BONELLI P., CUKIERMAN A., RIBEIRO CARROTT M., CARROTT P. Adsorption of volatile organic compounds onto activated carbon cloths derived from a novel regenerated cellulosic precursor. J. Hazard Mater. 177, (1), 175, 2010.

23. REN X., CHEN C., NAGATSU M., WANG X. Carbon nanotubes as adsorbents in environmental pollution management: A review. Chem. Eng. J. 170, (2-3), 395, 2011.

24. XU J., SHENG T., HU Y., BAIG S., LV X., XU X. Adsorption-dechlorination of 2,4-dichlorophenol using two specified MWCNTs-stabilized $\mathrm{Pd} / \mathrm{Fe}$ nanocomposites. Chem. Eng. J. 219, 162, 2013.

25. LIU H., LIU W., ZHANG J., ZHANG C., REN L., Li Y. Removal of cephalexin from aqueous solutions by original and $\mathrm{Cu}$ (II)/Fe (III) impregnated activated carbons developed from lotus stalks Kinetics and equilibrium studies. J. Hazard Mater. 185, (2), 1528, 2011.

26. WU Q., LI Z., HONG H. Adsorption of the quinolone antibiotic nalidixic acid onto montmorillonite and kaolinite. Appl. Clay Sci., 74, 66, 2013.

27. XU L., DAI J., PAN J., LI X., HUO P., YAN Y., ZOU X., ZHANG R. Performance of rattle-type magnetic mesoporous silica spheres in the adsorption of single and binary antibiotics. Chem. Eng. J. 174, 221, 2011. 
